\title{
Bullous variant of idiopathic central serous chorioretinopathy
}

\author{
Dinesh K Sahu, P Namperumalsamy, George F Hilton, Nolan F de Sousa
}

\begin{abstract}
Background-Spontaneous bullous serous retinal detachment (RD) with subretinal exudation complicating idiopathic central serous chorioretinopathy (ICSC) is a rare and infrequently described clinical entity. Clinical observations are described on this variant form in 11 patients, the largest series reported to date.

Methods-13 eyes of 11 Indian patients having this entity were followed up clinically and angiographically for 12-24 months (retrospective, longitudinal). None of the patients had any previous history of other diseases nor were they on any medications. Four eyes received laser treatment (group A); nine eyes were not treated (group B).

Results-All 11 patients were male, aged 23-49 years (median 37 years). The clinical and photographic records revealed subretinal exudation and inferior bullous serous RD complicating ICSC with evidence of large, single or multiple, leaking retinal pigment epithelial detachments (PEDs) in all the cases. In group $A$, resolution of serous $R D$ occurred in 12 weeks (median) with a visual recovery of $\geqslant 20 / 30$ in three out of four eyes while in group $B$ resolution of serous retinal detachment was observed in 14 weeks (median) with eight out of nine eyes achieving a visual acuity of $\geqslant 20 / 30$. Subretinal fibrosis developed in two eyes in group $A$ and none of the eyes in group $B$. Conclusion-The disease is an exaggerated form of ICSC and can occur spontaneously without any history of corticosteroid therapy. Recognition of this atypical presentation is important to avoid inappropriate treatment. These observations suggest that with respect to the duration of the disease and the final visual outcome laser therapy offers no additional benefit over the natural course of this variant form of ICSC.

(Br f Ophthalmol 2000;84:485-492)
\end{abstract}

Department of Ophthalmology, University of California Medical

Center, San Francisco, California, USA

G F Hilton

Correspondence to: Dr Dinesh K Sahu, Manipal Hospital, 98 Rustom Bagh, Airport Road, Bangalore 560017 , India

mhds@vsnl.com

Accepted for publication 13 January 2000 graphic patterns, confirming his original theory. In 1966, Gass ${ }^{5}$ proposed the term ICSC to describe such entities in hyperkinetic, intense, otherwise healthy young or middle aged adults, predominantly males who developed one or more localised serous detachments while under emotional stress.

The pathogenesis of the disease involves breakdown in the permeability of choriocapillaris and RPE in one or more focal areas in the posterior fundus. Through this defect, fluid gains access to the subretinal space and thus produces an overlying detachment of the sensory retina. In most cases, this detachment resolves spontaneously with a good visual recovery. ${ }^{5-9}$ If it persists, laser treatment to the focal leaks outside the foveolar zone is effective in the faster resolution of the detachment. $^{5-8} 10-15$

On rare occasions, bullous serofibrinous exudative retinal detachment (RD) may occur in some patients with ICSC. ${ }^{16-32}$ In general, this atypical presentation is thought to be an exaggerated form of typical ICSC since there are large, single or multiple, leaking (blowout) pigment epithelial detachments (PEDs) which are often hidden underneath the cloudy subretinal exudation. Because of its peculiar clinical findings, it can present a diagnostic dilemma and may lead to inappropriate diagnoses of rhegmatogenous RD; or serous RD due to other causes. Several previously reported such cases underwent scleral buckling or cryopexy 222730 or cortocosteroid therapy. ${ }^{21-31} \mathrm{~A}$ correct diagnosis was usually made at a later date and subsequently the disease was observed to resolve slowly with subnormal visual acuity after laser photocoagulation in many of them.

Previous publications on this variant form of ICSC have described few, if any, patients who developed bullous exudative RD spontaneously in association with ICSC. Most of the previously reported cases were observed to develop this variant form of ICSC following corticosteroid therapy, ${ }^{16}{ }^{17}{ }^{21-31}$ organ transplantation, ${ }^{18}{ }^{19}$ haemodialysis, ${ }^{20}$ or in pregnant women. ${ }^{33}{ }^{34}$ Resolution of serous $\mathrm{RD}$ was noted in many of them on discontinuation of corticosteroids or after delivery and/or after laser photocoagulation. So far, only five cases have been reported in the English literature and one case elsewhere in which the bullous serofibrinous exudative RD developed spontaneously in association with ICSC. ${ }^{29-32}$

We present the largest series of cases with spontaneous serofibrous exudation and bullous retinal detachment complicating ICSC. We also have analysed the findings in our patients and compared them with the previously published cases in English literature. Furthermore, the final visual outcome and the duration of the disease in cases with the natural 
course of this variant form have been compared with those who received laser treatment, on a historical cohort basis. Finally, we would like to emphasise the importance of recognising this atypical presentation of ICSC to avoid incorrect diagnoses and inappropriate therapy.

\section{Materials and methods}

Records of all the patients with ICSC who presented with bullous serous $\mathrm{RD}$ and subretinal exudations were analysed retrospectively. These cases were evaluated at the retinavitreous service of Aravind Eye Hospital, Madurai, India.

We included only those patients who presented with ICSC associated with subretinal exudation and spontaneous bullous exudative $\mathrm{RD}$. We excluded patients with evidence of previous ocular surgery, co-existing ocular diseases, or trauma. Those with a systemic problem (based on historical evidence and cursory systemic examination), pregnancy, or taking corticosteroid therapy for other diseases were also excluded from the study. Based on these criteria, 15 eyes of the 13 patients were found to have the disease and formed the basis of our study.

All the cases underwent a complete ocular examination including best corrected visual acuity, slit lamp examination, direct and indirect ophthalmoscopy, and +90D and/or fundus contact lens biomicroscopy. Additionally, fundus photographs were taken and fluorescein angiography was performed, wherever possible, at the first visit and after the clinical resolution of serous RD. All cases were followed up every 2 weeks for the first 4 months, then monthly for a minimum of 10 months, and 3 monthly thereafter.

The first two unilateral cases were misdiagnosed at the initial visit and were treated with systemic or periocular corticosteroids. At the subsequent visit the correct diagnosis was made and they were then treated with laser. To avoid bias and complexity of the study, these cases were excluded from the study.

Since the definitive role of the laser treatment has not been established in this variant

Table 1 Patient profile and clinical characteristics of bullous variant of ICSC in present series

\begin{tabular}{|c|c|c|c|c|c|c|c|c|c|c|c|c|}
\hline \multirow{2}{*}{$\begin{array}{l}\text { Case } \\
\text { No }\end{array}$} & \multirow[b]{2}{*}{ Age/sex } & \multirow[b]{2}{*}{ Laterality } & \multirow{2}{*}{$\begin{array}{l}V A \\
\text { affected } \\
\text { eye }\end{array}$} & \multicolumn{2}{|l|}{ Fundus } & \multirow{2}{*}{$\begin{array}{l}\text { Evidence of } \\
\text { subretinal } \\
\text { exudation }\end{array}$} & \multirow{2}{*}{$\begin{array}{l}\text { Fluorescein } \\
\text { angiography } \\
\text { affected eye }\end{array}$} & \multicolumn{2}{|c|}{ Treatment } & \multirow{2}{*}{$\begin{array}{l}\text { Interval between } \\
\text { first visit and } \\
\text { resolution of } \\
\text { subretinal fluid }\end{array}$} & \multirow{2}{*}{$\begin{array}{l}\text { Residual } \\
\text { changes }\end{array}$} & \multirow[b]{2}{*}{ Final VA } \\
\hline & & & & eye & Fellow eye & & & No $R x$ & Laser & & & \\
\hline 1 & $39 / \mathrm{M}$ & Right eye & $20 / 60$ & $\begin{array}{l}\text { Inferior } \\
\text { bullous } \\
\text { RD+PED }\end{array}$ & PED & Yes & $\begin{array}{l}2 \text { PEDs, } 1 \\
\text { leaking } \\
\text { PED + } \\
\text { Pooling }\end{array}$ & Yes & - & 14 weeks & $\begin{array}{l}\text { Minimal RPE } \\
\text { deg }\end{array}$ & $20 / 30$ \\
\hline 2 & $32 / \mathrm{M}$ & Left eye ${ }^{\star}$ & $20 / 60$ & $\begin{array}{l}\text { Teardrop } \\
\text { RD } \\
+ \text { PED }\end{array}$ & $\begin{array}{l}\text { RPE } \\
\text { changes + } \\
\text { laser } \\
\text { marks }\end{array}$ & Yes & $\begin{array}{l}1 \mathrm{PED}, 1 \\
\text { leak }+ \\
\text { pooling }\end{array}$ & Yes & - & 15 weeks & $\begin{array}{l}\text { Minimal RPE } \\
\text { deg }\end{array}$ & $20 / 30$ \\
\hline 3 & $40 / \mathrm{M}$ & Left eye & $20 / 80$ & $\begin{array}{l}\text { Inferior } \\
\text { bullous } \\
\text { RD } \\
+ \text { PED }\end{array}$ & Normal & Yes & $\begin{array}{l}1 \mathrm{PED}, 1 \\
\text { leak }+ \\
\text { pooling }\end{array}$ & - & Yes† & 12 weeks & $\begin{array}{l}\text { Laser marks + } \\
\text { RPE changes }\end{array}$ & $20 / 20$ \\
\hline \multirow[t]{2}{*}{4} & \multirow[t]{2}{*}{$43 / \mathrm{M}$} & \multirow[t]{2}{*}{ Both eyes } & $20 / 80$ & $\begin{array}{l}\text { Inferior } \\
\text { bullous } \\
\text { RD+PED }\end{array}$ & \multirow[t]{2}{*}{$\begin{array}{l}\text { Not } \\
\text { applicable }\end{array}$} & Yes & $\begin{array}{l}2 \text { PEDs, } 1 \\
\text { leaking } \\
\text { PED + } \\
\text { pooling }\end{array}$ & Yes & - & 12 weeks & $\begin{array}{l}\text { Minimal RPE } \\
\text { changes }\end{array}$ & $20 / 20$ \\
\hline & & & $20 / 60$ & $\begin{array}{l}\text { Inferior } \\
\text { bullous } \\
\text { RD+PED }\end{array}$ & & Yes & $\begin{array}{l}3 \text { leaking } \\
\text { PEDs }+ \\
\text { Pooling }\end{array}$ & - & Yes† & 10 weeks & $\begin{array}{l}\text { Minimal RPE } \\
\text { changes + laser } \\
\text { marks + } \\
\text { minimal } \\
\text { scarring }\end{array}$ & $20 / 30$ \\
\hline \multirow[t]{2}{*}{5} & \multirow[t]{2}{*}{$23 / \mathrm{M}$} & \multirow[t]{2}{*}{ Both eyes } & $20 / 200$ & $\begin{array}{l}\text { Inferior } \\
\text { bullous } \\
\text { RD+PED }\end{array}$ & \multirow[t]{2}{*}{$\begin{array}{l}\text { Not } \\
\text { applicable }\end{array}$} & Yes & $\begin{array}{l}2 \text { PEDs, } 1 \\
\text { leak }+ \\
\text { pooling }\end{array}$ & Yes & - & 14 weeks & $\begin{array}{l}\text { Minimal RPE } \\
\text { changes }\end{array}$ & $20 / 20$ \\
\hline & & & $20 / 80$ & $\begin{array}{l}\text { Inferior } \\
\text { bullous } \\
\text { RD+PED }\end{array}$ & & Yes & $\begin{array}{l}1 \text { PED, } 1 \\
\text { leak }+ \\
\text { pooling }\end{array}$ & - & Yes† & 12 weeks & $\begin{array}{l}\text { Minimal RPE } \\
\text { changes + laser } \\
\text { marks }\end{array}$ & $20 / 30$ \\
\hline 6 & $30 / \mathrm{M}$ & Right eye & $20 / 400$ & $\begin{array}{l}\text { Huge tear } \\
\text { drop } \\
\text { RD+PED }\end{array}$ & PED & Yes & $\begin{array}{l}1 \text { leaking } \\
\text { PED + } \\
\text { pooling }\end{array}$ & Yes & - & 16 weeks & $\begin{array}{l}\text { RPE deg } \\
\text { involving } \\
\text { macula }\end{array}$ & $20 / 40$ \\
\hline 7 & $49 / \mathrm{M}$ & Left eye & $20 / 400$ & $\begin{array}{l}\text { Inferior } \\
\text { bullous } \\
\mathrm{RD}+ \\
\text { PED }\end{array}$ & $\begin{array}{l}\text { RPE } \\
\text { changes + } \\
\text { laser } \\
\text { marks }\end{array}$ & Yes & $\begin{array}{l}2 \text { PEDs, } 2 \\
\text { leaks+ } \\
\text { pooling }\end{array}$ & Yes & - & 12 weeks & $\begin{array}{l}\text { Minimal RPE } \\
\text { deg }\end{array}$ & $20 / 30$ \\
\hline 8 & $32 / \mathrm{M}$ & Right eye & $20 / 400$ & $\begin{array}{l}\text { Inferior } \\
\text { bullous } \\
\text { RD + } \\
\text { PED }\end{array}$ & Normal & Yes & $\begin{array}{l}3 \text { PEDs, } 1 \\
\text { leak } \\
\text { +pooling }\end{array}$ & - & Yes† & 14 weeks & $\begin{array}{l}\text { Minimal RPE } \\
\text { deg + laser } \\
\text { marks + } \\
\text { minimal } \\
\text { scarring }\end{array}$ & $20 / 40$ \\
\hline 9 & $35 / \mathrm{M}$ & Right eye & $20 / 100$ & $\begin{array}{l}\text { Inferior } \\
\text { bullous } \\
\text { RD+PED }\end{array}$ & PED & Yes & $\begin{array}{l}1 \text { PED, } 1 \\
\text { leaking } \\
\text { PED + } \\
\text { pooling }\end{array}$ & Yes & - & 12 weeks & $\begin{array}{l}\text { RPE } \\
\text { degeneration }\end{array}$ & $20 / 30$ \\
\hline 10 & $38 / \mathrm{M}$ & Right eye & $20 / 60$ & $\begin{array}{l}\text { Inferior } \\
\text { bullous } \\
\text { RD+PED }\end{array}$ & PED & Yes & $\begin{array}{l}1 \text { leaking } \\
\text { PED + } \\
\text { pooling }\end{array}$ & Yes & - & 14 weeks & $\begin{array}{l}\text { Minimal RPE } \\
\text { degeneration }\end{array}$ & $20 / 20$ \\
\hline 11 & $41 / \mathrm{M}$ & Right eye & $20 / 100$ & $\begin{array}{l}\text { Inferior } \\
\text { bullous } \\
\text { RD+PED }\end{array}$ & Normal & Yes & $\begin{array}{l}1 \text { leaking } \\
\text { PED + } \\
\text { pooling }\end{array}$ & Yes & - & 14 weeks & $\begin{array}{l}\text { Minimal RPE } \\
\text { degeneration }\end{array}$ & $20 / 20$ \\
\hline
\end{tabular}

$\mathrm{RD}=$ retinal detachment $\mathrm{PED}=$ pigment epithelial detachment; $\mathrm{RPE}=$ retinal pigment epithelium; ICSC = idiopathic central serous chorioretinopathy. ${ }^{\star}$ Had previous history of ICSC in fellow eye. †Laser done within 1 week after first visit. 
Table 2 Summary of previously published cases of central serous chorioretinopathy with bullous retinal detachment

\begin{tabular}{|c|c|c|c|c|c|c|c|c|c|c|c|}
\hline \multirow[b]{2}{*}{ Author/year } & \multirow{2}{*}{$\begin{array}{l}\text { Case } \\
\text { No }\end{array}$} & \multirow[b]{2}{*}{ Age/sex } & \multirow[b]{2}{*}{ Laterality } & \multirow{2}{*}{$\begin{array}{l}\text { VA affected } \\
\text { eye }\end{array}$} & \multirow[b]{2}{*}{ Fundus } & \multirow{2}{*}{$\begin{array}{l}\text { Evidence of } \\
\text { subretinal } \\
\text { exudation }\end{array}$} & \multicolumn{2}{|c|}{ Treatment } & \multirow{2}{*}{$\begin{array}{l}\text { Interval } \\
\text { between first } \\
\text { visit and } \\
\text { resolution of } \\
\text { the disease }\end{array}$} & \multirow{2}{*}{$\begin{array}{l}\text { Residual } \\
\text { changes }\end{array}$} & \multirow[b]{2}{*}{ Final VA } \\
\hline & & & & & & & None & Laser & & & \\
\hline $\begin{array}{l}\text { Gass } / 1973^{29} \\
\text { (series of five } \\
\text { patients) }\end{array}$ & $3^{\star}$ & $37 / \mathrm{M}$ & Right eye & $20 / 50$ & $\begin{array}{l}\text { Inferior } \\
\text { bullous RD + } \\
\text { PED }\end{array}$ & Yes & - & $\begin{array}{l}\text { Ruby } \\
\text { laser }\end{array}$ & 3 weeks & NS & $20 / 30$ \\
\hline \multirow[t]{3}{*}{$\begin{array}{l}\text { Benson } / 1980^{30} \\
\text { (series of four } \\
\text { patients) }\end{array}$} & $1^{\star}$ & $54 / \mathrm{F}$ & $\begin{array}{l}\text { Right eye } \\
\text { first }\end{array}$ & NS & $\begin{array}{l}\text { Inferior } \\
\text { bullous RD }\end{array}$ & NA & - & $\ddagger$ & NS & $\begin{array}{l}\text { No fluid } \\
\text { subretinal } \\
\text { gliosis }\end{array}$ & $\mathrm{HM}$ \\
\hline & & & $\begin{array}{l}\text { Left eye after } \\
3 \text { years }\end{array}$ & NS & $\begin{array}{l}\text { Inferior } \\
\text { bullous RD + } \\
\text { PED }\end{array}$ & NA & & Argon & & NS & $\begin{array}{l}20 / 40 \text { (9 years } \\
\text { later) }\end{array}$ \\
\hline & $3^{\star}$ & $42 / \mathrm{M}$ & Right eye $†$ & $20 / 80$ & $\begin{array}{l}\text { Inferior } \\
\text { bullous RD + } \\
\text { PED }\end{array}$ & Yes & - & $\begin{array}{l}\text { Argon } \\
\text { (twice) }\end{array}$ & NS & NS & $\begin{array}{l}20 / 20(7 \\
\text { months later })\end{array}$ \\
\hline \multirow[t]{3}{*}{$\begin{array}{l}\text { Schatz/1995 } \\
\text { (series of six } \\
\text { patients) }\end{array}$} & $1^{\star}$ & $38 / \mathrm{M}$ & $\begin{array}{l}\text { Right eye } \\
\text { first }\end{array}$ & $20 / 400$ & $\begin{array}{l}\text { Inferior } \\
\text { bullous RD + } \\
\text { PED }\end{array}$ & Yes & - & - & 7 months & $\begin{array}{l}\text { Subretinal } \\
\text { fibrosis }\end{array}$ & $\mathrm{HM}$ \\
\hline & $2^{\star}$ & $53 / \mathrm{M}$ & $\begin{array}{l}\text { Left eye after } \\
4 \text { months }\end{array}$ & NS & ICSC + PED & Yes & & - & 2 months & $\begin{array}{l}\text { Minimal RPE } \\
\text { changes }\end{array}$ & $20 / 30$ \\
\hline & $2^{\star}$ & $53 / \mathrm{M}$ & Right eye & HM & $\begin{array}{l}\text { Inferior } \\
\text { bullous RD + } \\
\text { PED + } \\
\text { subretinal } \\
\text { fibrosis }\end{array}$ & Yes & - & - & 3 months & $\begin{array}{l}\text { Subretinal } \\
\text { scarring and } \\
\text { fibrosis }+ \\
\text { Persistent RD }\end{array}$ & HM \\
\hline
\end{tabular}

ICSC = idiopathic central serous chorioretinopathy; $\mathrm{VA}=$ visual acuity; RD = retinal detachment; NS = not stated; PED = pigment epithelial detachment; RPE = retinal pigment epithelium; $\mathrm{HM}=$ hand movements.

${ }^{\star}$ Remaining cases of the series developed bullous RD following corticosteroid therapy.

$\dagger$ Had previous history of ICSC.

$\ddagger$ Scleral buckling was done.

form of ICSC, the remaining cases were treated either with laser photocoagulation or no treatment was given depending upon the patient's consent after explaining the benefits and risks of the laser treatment. Thus, of the
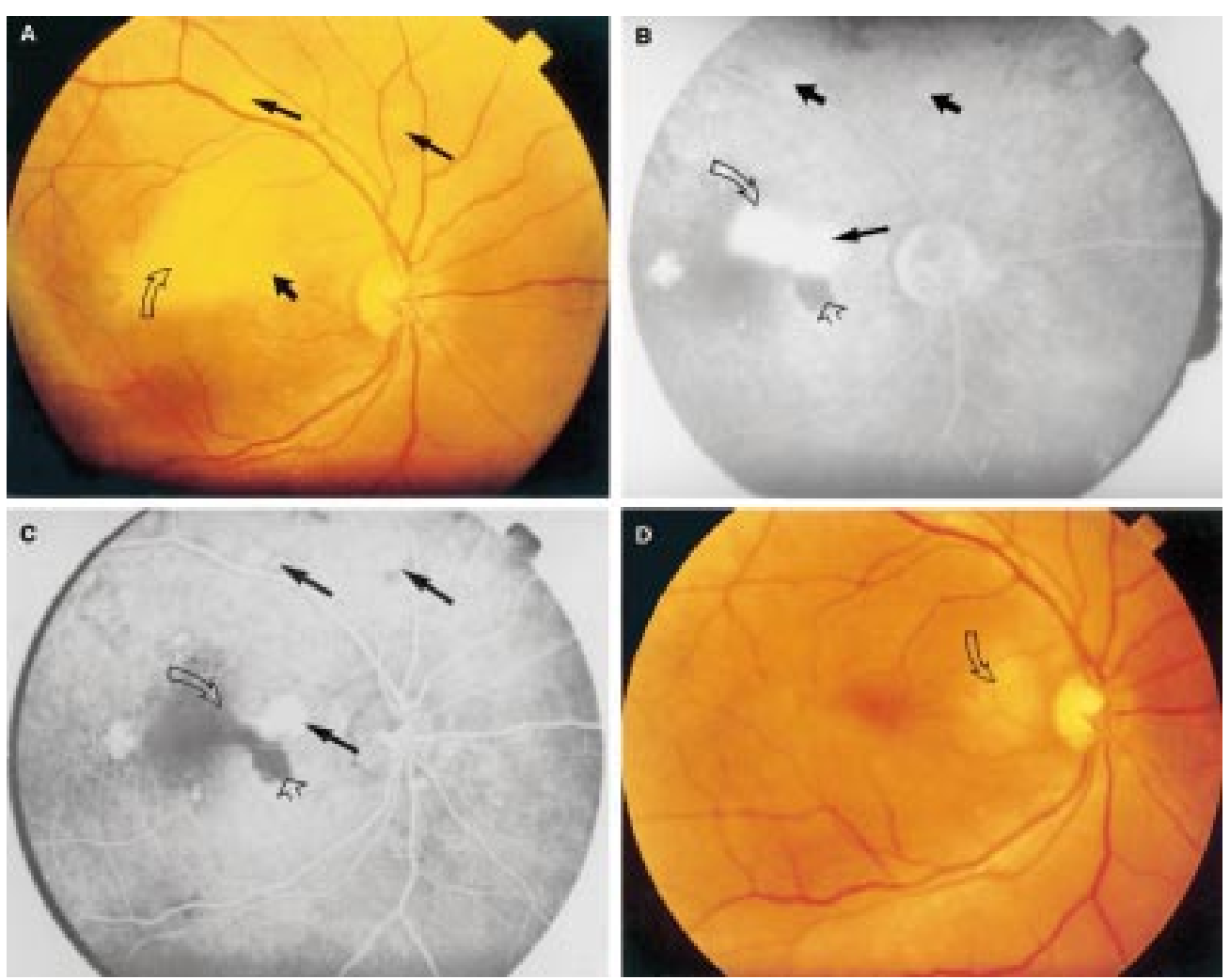

Figure 1 Case 4 right eye. (A) Fundus appearance at presentation showing two pigment epithelium detachments (PEDs) outside the superior temporal arcade (thin solid arrows). Notice a subtle PED nasal to the fovea (thick solid arrow) in the vicinity of subretinal exudation (open arrow). (B) Midphase fluorescein angiogram demonstrating multiple PEDs (solid arrows). Hypofluorescent areas are due to subretinal exudation (open arrow) and a hidden PED underneath the subretinal exudation (open arrowhead). (C) Late phase fluorescein angiogram showing multiple PEDs (thick solid arrows), a leaking PED (thin solid arrow), staining of subretinal exudation (open arrow), and persistent hypofluorescence due to a PED (open arrowhead) hidden under subretinal exudation. (D) Fundus appearance 14 weeks after onset (non-laser treated) showing near total resolution of subretinal exudation temporal to the disc (open arrow). 
produce a light to medium intensity coagulation using 100-200 $\mu \mathrm{m}$ spot size, $0.1-0.2$ second exposure time, and 100-300 mW power. In the bilateral cases (cases 4 and 5), one eye was treated with laser while the fellow eye was not treated. These cases were important because they provided us with unique setting to compare the efficacy of laser treated eye with the non-laser treated fellow eye in the same individual.

The disease was considered to be resolved when the subretinal exudation and serous RD were absent on +90D biomicroscopy; and fluorescein angiography showed no active leakage.

\section{Results}

From 1993 through 1995, 13 eyes of 11 patients with a final diagnosis of ICSC with
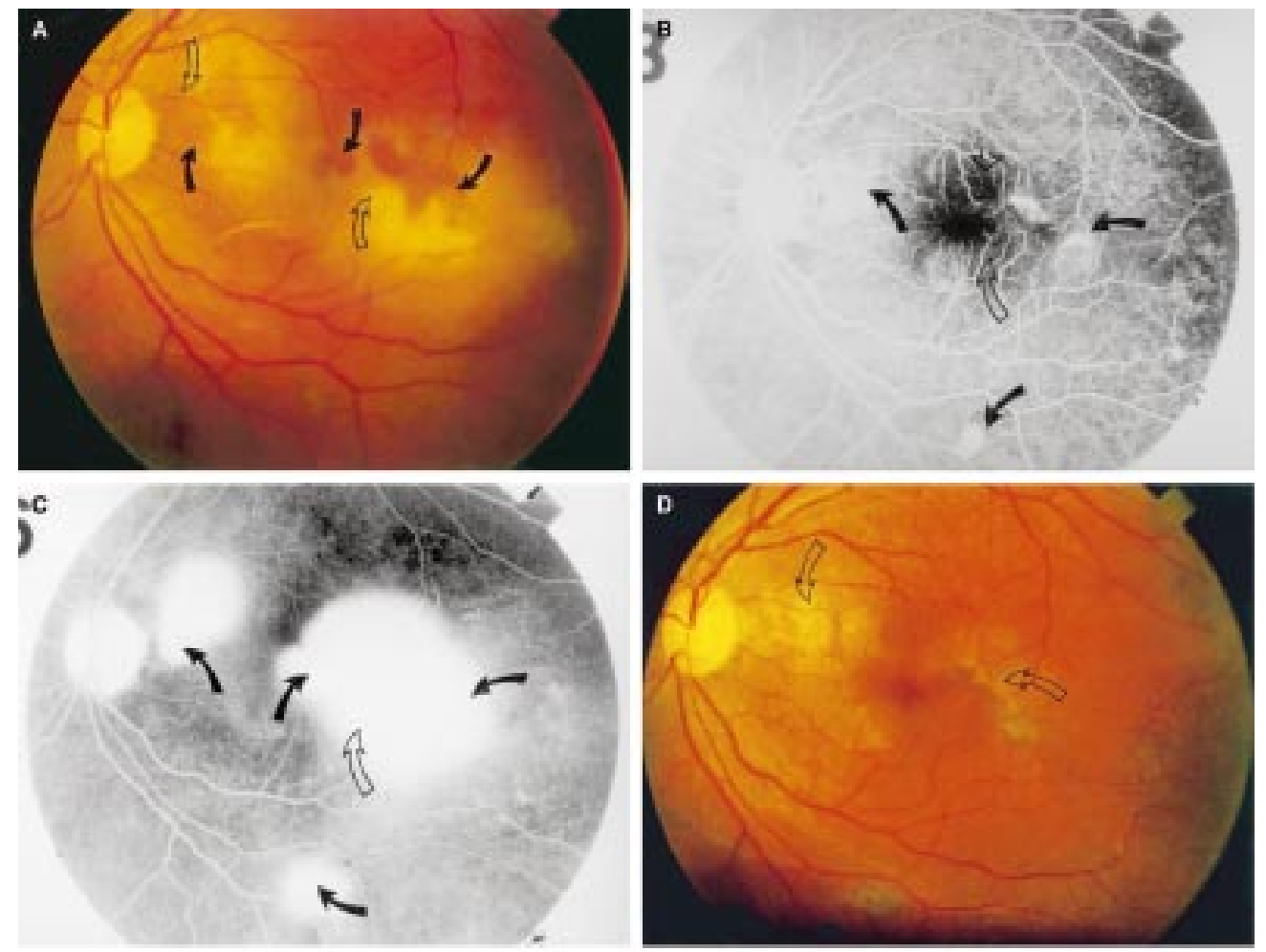

spontaneous bullous serofibrinous exudative RD met the study criteria and were included in the study. The patient profiles and clinical characteristics of these patients are summarised in Table 1 while Table 2 summarises the findings of the previously published similar cases in the English literature.

All 11 cases were males and came from the southern part of India. None of the patients had any systemic or pre-existing ocular disease, nor were they taking any medications as precluded by historical evidence and a cursory systemic examination. They were all employed in working conditions considered to be stressful and experienced frequent episodes of emotional stress. The median interval between the onset of the symptoms and the first visit was 2-3 weeks. Nine patients were unilateral while remaining two were bilateral and showed

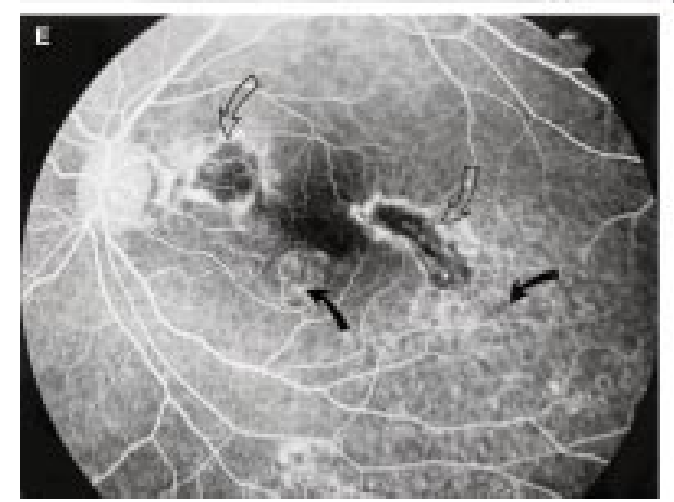

Figure 2 Case 4 left eye. (A) Fundus appearance at presentation demonstrating massive subretinal exudation and serous retinal detachment in the posterior pole. Notice hidden PEDs (solid arrows) in the vicinity of subretinal exudation (open arrows). (B) Midphase fluorescein angiogram demonstrating multiple PEDs (solid arrows), and hypofluorescent areas are due to a hidden PED (open arrowhead) and subretinal exudation (open arrow). (C) Late phase fluorescein angiogram showing leakage from the edges of PEDs (solid arrows), and staining of the subretinal exudation (open arrow). (D) Fundus appearance 12 weeks after laser photocoagulation showing subretinal fibrotic membrane around the fovea (open arrows). (E) Late phase angiogram 16 weeks after laser photocoagulation showing substantial amount of RPE degeneration (solid arrows) and subretinal fibrotic membranes (open arrows). 
Table 3 Bullous variant of ICSC: an overview of the results of laser treated and non-laser treated cases

\begin{tabular}{|c|c|c|}
\hline Variables & Non-lasered group (B) & Laser treated group $(A)$ \\
\hline Age (years) & 23-49 (mean 39.7 (SD 7.7), median 38) & 23-43 (mean 34.5 (SD 8.9), median 36) \\
\hline Sex & All males & All males \\
\hline Duration of symptoms (weeks) & $2-3($ median 2.4$)$ & $2-3$ (median 2.5$)$ \\
\hline No of eyes & 9 & 4 \\
\hline $\begin{array}{l}\text { Time interval between first visit and } \\
\text { institution of laser therapy }\end{array}$ & Not applicable & 1 week \\
\hline $\begin{array}{l}\text { Time interval between first visit and } \\
\text { resolution of subretinal exudation } \\
\text { (weeks) }\end{array}$ & $4-6($ mean $4.8(0.8)$, median 5$)$ & 4-6 (mean $4.8(1.0)$, median 4.5$)$ \\
\hline $\begin{array}{l}\text { Time interval between first visit and } \\
\text { resolution of serous RD (weeks) }\end{array}$ & 12-16 (mean $13.6(1.3)$, median 14$)$ & 10-14 (mean $12.0(1.6)$, median 12$)$ \\
\hline $\begin{array}{l}\text { Residual changes after resolution of the } \\
\text { disease }\end{array}$ & $\begin{array}{l}\text { Minimal RPE changes in posterior pole } \\
\text { and inferiorly (all } 9 \text { eyes) }\end{array}$ & $\begin{array}{l}\text { Minimal RPE changes in posterior pole } \\
\text { and inferiorly (all } 4 \text { eyes) }+ \text { minimal } \\
\text { subretinal fibrosis }(2 \text { eyes })\end{array}$ \\
\hline \multicolumn{3}{|l|}{ Visual acuity at first visit } \\
\hline $20 / 60-20 / 100$ & 6 eyes $(66.6 \%)$ & 3 eyes $(75 \%)$ \\
\hline $20 / 200$ or worse & 3 eyes $(33.3 \%)$ & 1 eye $(25 \%)$ \\
\hline \multicolumn{3}{|l|}{ Visual acuity after resolution } \\
\hline $20 / 2-20 / 30$ & 8 eyes $(89 \%)$ & 3 eyes $(75 \%)$ \\
\hline $20 / 40$ & 1 eye $(11 \%)$ & 1 eye $(25 \%)$ \\
\hline
\end{tabular}

subretinal exudation with bullous $\mathrm{RD}$ in both eyes simultaneously at the time of presentation (cases 4 and 5). Many of them (eight patients) had had one or more episodes of ICSC in one or both the eyes in the past.

At presentation, the best corrected visual acuity was between $20 / 60$ to $20 / 100$ in nine eyes and 20/200 or worse in four eyes. Anterior segment was normal and there were no vitreous cells in any of the patients.

Ophthalmoscopy revealed the presence of yellow-white subretinal exudation in the posterior pole in the affected eyes (Figs $1 \mathrm{~A}$ and $2 \mathrm{~A}$ ) with inferior bullous $\mathrm{RD}$ extending up to the superior arcade in the supine position in 11 eyes. The remaining two eyes had evidence of a large "teardrop" $\mathrm{RD}$ (cases 2 and 6) - that is, had localised posterior pole serous detachment which was connected to a large inferior bullous $\mathrm{RD}$ through a narrow track. In all the affected eyes one or more PEDs were detected in the vicinity of subretinal exudation or underneath the serous $\mathrm{RD}$ in the posterior pole (Figs 1A and 2A). These PEDs had a relatively larger size than those seen in the typical ICSC and frequently showed leakage from the edges of the PEDs (Figs 1B, C and 2B, C). Four unilateral cases (cases 1, 6, 9, and 10) showed evidence of PEDs and RPE degeneration whereas another two unilateral cases (cases 2 and 7) showed old laser marks and RPE degeneration in the uninvolved fellow eyes.

Fluorescein angiography was performed in all the cases (Table 1) which revealed one or more PEDs (one PED, five eyes; two PEDs, three eyes; three PEDs, five eyes). Few of them showed leakage from the edges of the PED (Figs 1C and 2C). Apart from these leaking PEDs, separate focal leaks were also observed (one leak, six eyes; two leaks, one eye; multiple leaks, one eye). Early hypofluorescence was noticed in the areas of subretinal exudation and/or underlying PEDs (Figs $1 \mathrm{~B}, \mathrm{C}$ and $2 \mathrm{~B}$ ) while late phase angiogram showed staining of subretinal exudation and pooling of the dye around the focal leaks and leaking (blowout) PEDs (Figs 1C and 2C).

For descriptive purpose, depending on the treatment modalities, all 13 eyes were divided into two groups-laser treated (group A) and non-laser treated (group B). Group A contained four eyes (cases 3, 4 left eye, 5 left eye, and 8) in which laser photocoagulation was performed. The patients ranged in age from 23 to 43 years (mean 34.5 (SD 8.9)) years). The duration of visual symptoms was 2-3 weeks and the visual acuities were $20 / 60$ to $20 / 400$. Fluorescein angiography demonstrated presence of one PED and one leak (cases 3 and 5 left eye), three leaking PEDs (case 4 left eye, Fig 2B, C), and three PEDs and one leak (case 8). All these leaks were outside the foveal avascular zone. In these cases, the resolution of subretinal exudation occurred in 4-6 weeks (mean 4.8 (1.0) weeks, median 4.5 weeks) whereas serous $\mathrm{RD}$ was resolved in 10-14 weeks (mean 12.0 (1.6) weeks, median 12 weeks). Two of the eyes in this group (cases 4 left eye and 8) developed subretinal fibrotic membrane after resolution of the disease (Fig $2 \mathrm{D}$ and $2 \mathrm{E}$ ).

Group B contained nine eyes which were not treated with laser. The patients ranged in age from 23-49 years (mean 39.7 (7.7) years). The duration of visual symptoms was 2-3 weeks and the visual acuities were $20 / 60$ to $20 / 400$. Fluorescein angiography revealed presence of one or more leaking PEDs and few focal leaks (Fig 1B, C). In these cases the resolution of the subretinal exudation occurred in 4-6 weeks (mean 4.8 (0.8) weeks, median 5 weeks) and resolution of serous $\mathrm{RD}$ was observed in 12-16 weeks (mean 13.6 (1.3) weeks, median 14 weeks). None of the eyes in this group showed any evidence of subretinal fibrotic membrane after resolution (Fig 1D).

An overview of the results of group A and group $\mathrm{B}$ is given in the Table 3 . Both the groups were analysed on a historical cohort basis. There was no significant difference between the two groups for the resolution of subretinal exudation $(p=0.96)$ or resolution of serous retinal detachment $(\mathrm{p}=0.16)$. Visual acuity was also analysed and no significant difference was found between the two groups at first visit $(p=0.73)$ or after resolution of the disease $(\mathrm{p}=0.84)$. A final visual acuity of $20 / 30$ or better was obtained by three $(75 \%)$ eyes in group A and 9 (89\%) eyes in group B. 
All cases were followed up at a gradually increasing interval for 12-24 months (median 13.5 months) and none of them showed any recurrence of the disease.

\section{Discussion}

The concept of spontaneous bullous serofibrinous exudative RD complicating ICSC is complex and confusing; and it is further complicated by reports of similar cases following corticosteroid therapy ${ }^{161^{21-31}}$ or during pregnancy. ${ }^{33} 34$ From a diagnostic and management standpoint, this variant of ICSC must be distinguished from rhegmatogenous $\mathrm{RD}$ or serous RD due to Harada's disease, posterior scleritis, multifocal chorioretinitis, choroidal tumour mass, or uveal effusion syndrome. As outlined in the previously published reports, ${ }^{16-32}$ a combination of ophthalmoscopic and angiographic findings is usually helpful in the establishment of the correct diagnosis. These include absence of vitreous cells, confinement of the yellow-white lesion to the outer retinal layers with single or multiple PEDs, the shifting nature of the subretinal fluid with fluctuating visual acuity, and absence of retinal breaks. Finally, fluorescein angiography is recommended which is proved to be an essential and invaluable diagnostic tool in confirming the diagnosis.

Most of the previously reported cases to date were noted to have this variant form of ICSC following corticosteroid therapy, ${ }^{16}{ }^{17}{ }^{21-31}$ organ transplantation, ${ }^{18}{ }^{19}$ or haemodialysis. ${ }^{20}$ In other instances, it was observed during pregnancy. ${ }^{33} 34$ The present series, the largest to date, differs from the other published reports primarily with the identification of this seemingly discrete variant form of ICSC in otherwise healthy young males with no history of corticosteroid therapy or organ transplantation. A review of the English literature revealed only five such cases in three different reports $^{29-31}$ (Table 2) and one case elsewhere. ${ }^{32}$ In 1973, Gass reported a series of five cases having bullous serofibrinous exudative $\mathrm{RD}$ in association with ICSC. ${ }^{29}$ Only one of them had spontaneous development of bullous $\mathrm{RD}$ whereas in remaining cases it was observed after corticosteroid therapy either for the treatment of the disease itself or on suspicion of an underlying inflammatory process. A good visual outcome was seen following laser treatment in that particular case. Subsequently, Benson et al in 1980, described two similar cases in their report on a series of four patients. ${ }^{30}$ One patient was treated with laser photocoagulation with good visual recovery while in the other scleral buckling was performed as a result of misdiagnosis. The remaining two cases of their series developed bilateral bullous RD following corticosteroid therapy as described by Gass earlier. Later in 1995, Schatz et al published a report of six patients with subretinal fibrosis following ICSC. ${ }^{31}$ Only two of them had spontaneous bullous serous RD in association with ICSC and were reported to have developed subretinal fibrosis following the natural course of the disease. However, both the cases had systemic hypertension and had undergone some extraocular surgery before the onset of the disease. Under these circumstances, an increased level of catecholamines is expected to be present in these cases which are known to have an adverse effect on the course of the disease..$^{5635}$ The present report contains the largest series of cases with this variant form of ICSC. The age group of the previously reported cases varied from 37 to 54 years with $80 \%$ of them being males. In our series, all 11 cases were males in the age group 23-49 years. The disease was found to be unilateral in $85 \%$ of our cases and most of them had experienced one or more episodes of ICSC in the past, similar to the previously reported cases. As far as the laser treatment of such cases is concerned, its efficacy has not been well established since the disease was not allowed to run is natural course in most of the previously reported cases. ${ }^{29-31}$ In the present series, the eyes were either treated with laser (four eyes) or not treated (nine eyes). Clinical observations of these cases over a period of 12-24 months (Table 3) showed that there was no significant difference between laser treated (group A) and non-laser treated eyes (group B) with regard to resolution of the disease $(\mathrm{p}=$ $0.16)$ and final visual outcome $(p=0.84)$. We also had two bilateral simultaneous cases (cases 4 and 5) in which one eye was treated with laser while the fellow eye is not treated. These two cases provided us with a unique setting to compare the laser treated eyes with non-laser treated eyes in the same individual since all variables were perfectly matched. There was not much difference between the two eyes in these cases with regard to resolution of subretinal exudation and serous $\mathrm{RD}$, and the final visual acuity. Although the resolution of serous RD occurred 2 weeks earlier in laser treated eyes, subretinal fibrotic membrane developed in one laser treated eye (case 4 left eye, Fig 2D, E) while the final visual acuity was better in non-laser treated eyes (Table 1).

These observations suggest that the natural course of this variant form of ICSC is as good as treatment with laser photocoagulation as far as the duration of the disease and final visual outcome are concerned. From the literature and our series, it is evident that in the majority of these cases, the leaks and blowout PEDs are found in the vicinity of the subretinal exudation. Through these intensive leaks, proteins and fibrinogen escape into the subretinal space. We presume that the presence of this thick subretinal exudation over leaking sites may seal the site of leakage mechanically, thus preventing further seepage of fluid into the subretinal space. This may result in spontaneous partial or complete closure of the leaking areas and hence limits the progression of serous RD. Furthermore, the subretinal exudation is fibrinous in nature. ${ }^{623}{ }^{236}$ Fibrin is a well known stimulus for the ingrowth of fibroblasts which may cause partial resolution of the exudation and can lead to formation of a subretinal fibrotic membrane..$^{23-3133}$ In our series, two cases developed such subretinal 
fibrotic membrane following laser treatment (group A) whereas none of the cases from group B developed subretinal fibrotic membrane on resolution of the disease. It is difficult to ascertain whether formation of such fibrotic membranes depend upon the severity of the subretinal exudation or fibroblastic reaction incited by a low grade inflammation that follows laser application.

Taking into consideration the previously reported cases of ICSC with bullous exudative $\mathrm{RD}$ following corticosteroid therapy, ${ }^{21-31}$ our cases differ from them in many aspects. Most of these cases have been reported to have typical ICSC initially and then later to have developed bilateral bullous exudative RD following institution of systemic corticosteroid therapy either for the treatment of ICSC itself or due to misdiagnoses. In many of them the disease was resolved slowly over many months on discontinuation of corticosteroids and/or after laser photocoagulation with a subnormal visual acuity and substantial amounts of subretinal fibrosis. On the other hand, the cases in the present series developed bullous exudative RD spontaneously and none of them received corticosteroid therapy. Most of them were unilateral and resolved faster with a good visual outcome. Since it has been concluded from previous reports ${ }^{6} 161721-313738$ that systemic corticosteroid therapy may cause severe exacerbation of retinal detachment and lasting visual loss in some patients with ICSC, this may explain the variations that have been noted between the previously reported cases and our patients.

The exact aetiology of ICSC with spontaneous bullous exudative RD is not known. However, experimental production of ICSC in monkeys by intravenous adrenaline (epinephrine) injections, ${ }^{39}$ and increased levels of catecholamines in patients with type A personality trait have led to the implication of catecholamines in the aetiology of ICSC. $^{40}$ It is possible that some individuals may be hyperresponsive to the increased level of catecholamines for some unknown reason and thus the ability of the eye to repair the focal defects is impaired, resulting in the spontaneous development of bullous serofibrinous exudative RD as also suggested by Gass. ${ }^{6}{ }^{23}$ Although this variant form is pathophysiologically similar to the typical form of ICSC, the clinical presentation remains sufficiently different between these forms to set them apart. This becomes relevant as far as management and prognosis are concerned. Management of this variant form may represent a potential source of confusion unless the correct diagnosis is well established during the first visit of the patient wherein other inflammatory diseases of the retina and choroid and rhegmatogenous RD are excluded. The prognosis for a good visual outcome is generally favourable if the disease is allowed to run its natural course in this variant form of ICSC. Concurrent laser treatment may adversely influence the final outcome as outlined in this study.

Since our sample size was small and the cases were not randomised for laser treatment or non-laser treatment, a prospective randomised study involving a large number of patients having this variant form of ICSC could possibly establish the efficacy of laser treatment or alternative therapy.

The authors would like to thank Dr SR Mamatha, consultant, retina vitreous services of Aravind Eye Hospital, Madurai, Tamilnadu for her valuable assistance in the preparation of this manuscript.

1 Von Graefe A. Ueber centrale recidiverende retinitis. Graefes Arch Clin Exp Ophthalmol 1866;12:211-15.

2 Klein BA. Macular lesions of vascular origin II. Functional vascular conditions leading to damage of the macula lutea. Am $\mathcal{F}$ Ophthalmol 1953;36:1-13.

3 Maumenee AE. Serous and hemorrhagic disciform detachment of the macula. Trans Pacif Coast Oto-Ophthalmol Soc 1959;40:139-60.

4 Maumenee AE. Discussion of Gass JDM. Pathogenesis of hemorrhagic disciform lesion of the posterior ocular fundus. A histopathologic study. Presented to Wilmer fundus. A histopathologic study. Presented to

5 Gass JDM. Pathogenesis of disciform detachment of the neuroepithelium. II. Idiopathic central choroiodopathy. $\mathrm{Am}$ f Ophthalmol 1967;63:587-615.

6 Gass JDM. Stereoscopic atlas of macular diseases: diagnosis and treatment. 4th ed. St Louis: CV Mosby, 1997:52-70.

7 Spittznas M. Central serous retinopathy. In: Ryan SJ, ed. Retina. 2nd ed. Vol 2. St Louis: CV Mosby, 1994:1158-68. 8 Dellaporta A. Central serous retinopathy. Trans Am Ophthalmol Soc 1976;74:144-51.

9 Klein M, Van Buskirk M, Friedman E, et al. Experience with non-treatment of central serous choroidopathy. Arch Ophthalmol 1974;91:247-50.

10 Leaver P, Williams C. Argon laser photocoagulation in the treatment of central serous retinopathy. $\mathrm{Br} \mathcal{F}$ Ophthalmol 1979;63:674-7.

11 Landers M. Argon laser treatment of central serous chorioretinopathy. Ann Ophthalmol 1977;9:156-72.

12 Robertson D, Ilstrup D. Direct, indirect and sham laser photocoagulation in the management of central serous photocoagulation in the management of cen

13 Novak MA, Singerman LJ, Rice TA. Krypton and argon laser photocoagulation for central serous retinopathy. Retina 1987;7:162-9.

14 Flicker L, Vafidis G, While A, et al. Long term follow-up of a prospective trial of argon laser photocoagulation in the treatment of central serous retinopathy. $\mathrm{Br} \mathcal{F}$ Ophthalmol 1988;72:829-34.

15 Slusher MM. Krypton laser photocoagulation in treatment of central serous chorioretinopathy. Retina 1986;6:81-4.

16 Matsuo T, Nakayama T, Koyama T, et al. Multifocal pigment epithelial damages with serous retinal detachment in systemic lupus erythematosus. Ophthalmologica 1987; 195:97-102.

17 Jabs DA, Hanneken AM, Schachat AP, et al. Choroidopathy in systemic lupus erythematosus. Arch Ophthalmol 1988; 106: $230-4$.

18 Friberg TR, Eller AW. Serous retinal detachment resem-

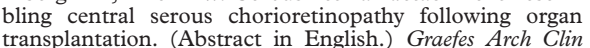
Exp Ophthalmol 1990;228:305-9.

19 Gass JDM, Slumovits TL, Fuller DG, et al. Posterior chorioretinopathy with retinal detachment after organ transplantation. Arch Ophthalmol 1992;110:1717-22.

20 Gass JDM. Bullous retinal detachment and multiple retinal pigment epithelium detachments in patients receiving haemodialysis. (Abstract in English.) Graefes Arch Clin Exp Ophthalmol 1992;230:454-8.

21 Dasatnik HR, Gutman FA. Bilateral exudative retinal detachment complicating systemic corticosteroid therapy in the presence of renal failure. Am F Ophthalmol 1996;122: 432-4.

22 Laatikainen L. Diffuse chronic retinal pigment epitheliopathy and exudative retinal detachment. Acta Ophthalmol 1994;72:533-6.

23 Gass JDM, Little H. Bilateral bullous exudative retinal detachment complicating idiopathic central serous chorioretinopathy during systemic corticosteroid therapy. Ophoretinopathy during systemic
thalmology 1995;102:737-47.

24 Tsukahara I, Morii F. A peculiar type of secondary detachment of retina. With special reference to central serous choroidopathy and peripheral uveitis. (Abstract in English.) fpn f Clin Ophthalmol (Tokyo) 1973;27:1003-8

25 Mimura Y, Hioki T, Yusa T, et al. Retinochoroidal affection associated with peripheral retinal detachment. II. Pathogenesis and differential diagnosis (Abstract in English.) $7 p n$ f Clin Ophthalmol (Tokyo) 1973;27:1015-20.

26 Tsukahara I, Uyama M. Central serous choroidopathy with bullous retinal detachment. (Abstract in English.) Graefes Arch Klin Exp Ophthalmol 1978;206:169-78.

27 Akiyama K, Kawamura M, Ogata T, et al. Retinal vascular loss in idiopathic central serous chorioretinopathy with bullous retinal detachment. Ophthalmology 1987;94:16059 .

28 Mazzuca D, Benson W. Central serous retinopathy: variants. Surv Ophthalmol 1986;31:170-4.

29 Gass JDM. Bullous retinal detachment - an unusual manifestation of idiopathic central serous choroidopathy. $A m \mathcal{F}$ Ophthalmol 1973;75:810-21. 
30 Benson WE, Shields JA, Annesley WH Jr, et al. Idiopathic central serous chorioretinopathy with bullous retinal detachment. Ann Ophthalmol 1980;12:920-4.

31 Schatz H, McDonald HR, Johnson RM, et al. Subretinal fibrosis in central serous chorioretinopathy. Ophthalmology 1995;102:1077-88.

32 Weiler W, Foerster $\mathrm{MH}$, Wessing A. Exudative retinal detachment, pigment epithelium tear and subretinal exudates in a case of CSR (Abstract in English.) Klin Monatsbl Augenheilkd 1991;99:450-3.

33 Gass JDM. Central serous chorioretinopathy and white subretinal exudation during pregnancy. Arch Ophthalmol 1991;109:677-81.

34 Quillen DA, Gass JDM, Brod RD, et al. Central serous retinopathy in women. Ophthalmology 1996;103:72-9.

35 Gelber GS, Schatz H. Loss of vision due to central serous chorioretinopathy following psychological stress. Am $\mathcal{f} P s y-$

chiatry 1987;144:46-50.
36 De Venecia G. Fluorescein angiographic smoke stack. Case pe Venecia G. Fluorescein angiographic smoke stack. Case
prestat Verhoeff society meeting, Washington DC, presentation at Ve

37 Wakakura $M$, Ischikawa S. An evaluation of corticosteroid therapy for central serous chorioretinopathy (Abstract in English.) Rinsho Ganka 1980;34:123-9.

38 Wakakura $\mathrm{M}$, Ishikawa S. Central serous chorioretinopathy complicating systemic corticosteroid treatment. $\mathrm{Br} \mathcal{F}$ Ophthalmol 1984;68:329-31.

39 Yoshioka H, Katsume Y, Akune H. Experimental central angiographic findings. Ophthalmologica 1982;185:168.

40 Yannuzzi LA. Type-A behavior and central serous chorioretinopathy. Retina 1987;7:111-30. 